\title{
Insulin Signaling Deficiency Produces Immobility in Caenorhabditis elegans That Models Diminished Motivation States in Man and Responds to Antidepressants
}

\author{
Julie Dagenhardt ${ }^{a}$ Angeline Trinh ${ }^{b}$ Halen Sumner ${ }^{d}$ Jeffrey Scott ${ }^{d}$ \\ Eric Aamodt ${ }^{c}$ Donard S. Dwyer ${ }^{a}$ b \\ Departments of a Pharmacology, Toxicology and Neuroscience, ${ }^{b}$ Psychiatry and ${ }^{c}$ Biochemistry and \\ Molecular Biology, LSU Health Sciences Center at Shreveport, and ${ }^{\mathrm{d} C e n t e n a r y ~ C o l l e g e, ~ S h r e v e p o r t, ~ L A, ~ U S A ~}$
}

\section{Keywords}

Antidepressants · Diabetes · Insulin · Major depression · Molecular psychiatry · Motivation · Schizophrenia

\begin{abstract}
Defects in insulin signaling have been reported in schizophrenia and major depressive disorder, which also share certain negative symptoms such as avolition, anhedonia, and apathy. These symptoms reflect diminished motivational states, which have been modeled in rodents as increased immobility in the forced swimming test. We have discovered that loss-of-function mutations in the insulin receptor (daf-2) and syntaxin (unc-64) genes in Caenorhabditis elegans, brief food deprivation, and exposure to DMSO produce immobility and avolition in non-dauer adults. The animals remain responsive to external stimuli; however, they fail to forage and will remain in place for $>12$ days or until they die. Their immobility can be prevented with drugs used to treat depression and schizophrenia and that reduce immobility in the forced swimming test. This includes amitriptyline, amoxapine, clozapine, and olanzapine, but not benzodiazepines and haloperidol. Recovery experiments confirm that immo-
\end{abstract}

\section{KARGER}

(C) 2017 S. Karger AG, Basel

E-Mail karger@karger.com

www.karger.com/mnp bility is induced and maintained by excessive signaling via serotonergic and muscarinic cholinergic pathways. The immobility response described here represents a potential protophenotype for avolition/anhedonia in man. This work may provide clues about why there is a significant increase in depression in patients with diabetes and suggest new therapeutic pathways for disorders featuring diminished motivation as a prominent symptom.

(c) 2017 S. Karger AG, Basel

\section{Introduction}

Defective insulin/IGF-1 signaling has been observed in major psychiatric illnesses, including schizophrenia and major depressive disorder (MDD). Interestingly, schizophrenia was formerly treated with insulin shock therapy [1]. More recent studies have documented abnormalities in glucose metabolism in schizophrenic patients [reviewed in 2] and revealed a deficit in IGF-1 along with concomitant insulin resistance in this population [3]. In a similar vein, patients with type 2 diabetes mellitus and insulin resistance show a 2 - to 3 -fold increase in the

Dr. Donard S. Dwyer

Department of Psychiatry, LSU Health Sciences Center at Shreveport 1501 Kings Highway

Shreveport, LA 71130 (USA)

E-Mail ddwyer@lsuhsc.edu 
prevalence of MDD compared to the general adult population or patients with other chronic diseases [4-6]. MDD and schizophrenia share an array of negative symptoms that are variously referred to as apathy, anhedonia, avolition, and social withdrawal $[7,8]$. Taken together, these observations suggest there might be common origins for the shared symptomatic behavior. We reasoned that reduced insulin signaling could produce changes in motivational states that underlie normal affective function. This is consistent with emerging ideas about a possible role for insulin signaling in depression [9].

Many psychiatric illnesses show characteristic disturbances in reward and motivational systems [10]. In schizophrenia, avolition is considered to be an established endophenotype $[11,12]$, whereas in MDD, anhedonia - or diminished pleasure-seeking - is a candidate marker for the disease $[13,14]$. Anhedonia is part of a larger negative symptom complex in depression that includes apathy. In fact, anhedonia and apathy both reflect reduced motivation to either experience pleasure or actively engage in life. Although avolition and apathy are terms that have been applied to differentially characterize symptoms of schizophrenia and depression, respectively, they actually describe the same phenomenon - diminished motivational states, which are common to various psychiatric disorders. Marin [15] and Starkstein and Leentjens [16] have defined disorders of diminished motivation as a decrease in goal-oriented thoughts and behavior in the absence of altered consciousness, attention deficits, language impairment, or sensorimotor loss.

Recently, we proposed the concept of "protophenotypes" - endophenotypes (disease markers) that are conserved across evolution - and demonstrated that altered social behavior in Caenorhabditis elegans is a suitable counterpart to asociality in man [17]. The validity of this line of reasoning is further supported by studies that investigate "emotion primitives," or rudiments of human emotional behavior, in Drosophila and C. elegans [18]. Because motivation is essential to drive behavior in all animals - to locate food, avoid harm, and find mates aspects of this system are likely to have been conserved through evolution and qualify as protophenotypes. Consequently, we hypothesized that knockdown of insulin/ IGF-1 signaling in C. elegans might alter goal-oriented behavior and serve as a protophenotype for diminished motivational states in MDD and schizophrenia.

As reported here, animals with loss-of-function mutations in the C. elegans insulin receptor (daf-2) or syntaxin (unc-64) genes become immobile, but not unresponsive, when subjected to brief food deprivation in the presence of dimethyl sulfoxide (DMSO). This immobility response is analogous to that observed in rodents in the forced swimming test, which is used to model despair in relation to affective disorders [19-21]. The goal of this work is to identify genetic and other factors that reduce fundamental, goal-oriented behavior and to identify pharmacological approaches to overcome the genetic defects. This work may lead to a better understanding of the molecular regulation of motivation and new therapeutic pathways for disorders featuring diminished motivation/avolition.

\section{Materials and Methods}

General Handling of C. elegans and the Strains Used

The C. elegans strains used for these experiments were obtained from the Caenorhabditis Genetics Center and include: N2 (wild type), DR1574 daf-2(e1391), DR1565 daf-2(m596), DR1942 daf-2 (e979), DR1568 daf-2(e1371), CB169 unc-31(e169), and CB246 unc-64(e246). C. elegans was cultured at $15^{\circ} \mathrm{C}$ according to standard growth conditions described previously $[17,22]$. For induction of immobility, the animals were shifted to $25^{\circ} \mathrm{C}$ (the restrictive temperature) overnight prior to use in the assay.

\section{Induction of Immobility (Diminished Motivational State)}

The loss-of-function mutations in insulin signaling are temperature sensitive and manifest at temperatures above $25^{\circ} \mathrm{C}$. The animals were grown on $90-\mathrm{mm}$ nematode growth medium (NGM) plates $\left(15^{\circ} \mathrm{C}\right)$ with food and $5 \mathrm{X}$ peptone and were then shifted to $25^{\circ} \mathrm{C}$ overnight $(16-18 \mathrm{~h})$. They were maintained in a well-fed state with ample food. Next, the animals were transferred with a platinum wire pick to standard 60-mm NGM plates with food in the absence (control) or presence of DMSO (1\% final concentration) for $90 \mathrm{~min}$. We then placed them on $90-\mathrm{mm}$ NGM plates without peptone or food and in the absence or presence of DMSO (1\%), depending on the experiment. This protocol is depicted in Table 1.

To prevent transfer of bacteria, we selected animals that were off the bacteria or we removed some from the bacteria to a region of the plate without bacteria and allowed them to crawl for 5-10 s before moving them to plates without food. At various times after transfer, we observed the animals individually for $5 \mathrm{~s}$ and scored them as "spontaneously moving" if they traveled more than 2 head lengths (about half their body length) in either direction as described elsewhere [23]. All incubation steps and observations were performed at $25^{\circ} \mathrm{C}$ or room temperature, respectively.

Reversal of Immobility with Pharmacological Agents

The drugs and neurotransmitters used in these studies were obtained from Sigma-Aldrich (St. Louis, MO, USA) or Tocris Bioscience (Bristol, UK). Clonazepam and diazepam were gifts from Dr. Nicholas Goeders (LSU Health Sciences Center at Shreveport). Olanzapine, clozapine, haloperidol, clonazepam, diazepam, amoxapine, loxapine, amitriptyline, cyproheptadine, ritanserin, and metergoline were dissolved in DMSO. The volume of drug-DMSO was taken into account when setting up the test plates containing DMSO, i.e., the total amount of DMSO was $1 \%$. Serotonin, dopa-
98

Mol Neuropsychiatry 2017;3:97-107

DOI: $10.1159 / 000478049$
Dagenhardt/Trinh/Sumner/Scott/

Aamodt/Dwyer 
Table 1. Time course of immobility response and effect of octanol

General protocol

NGM (5X peptone) plate plus food, $15^{\circ} \mathrm{C}$

NGM (5X peptone) plate plus food, $25^{\circ} \mathrm{C}$ overnight $(16-18 \mathrm{~h}$ )

$\downarrow$

NGM plate plus food ( \pm DMSO + solvent or drug), $25^{\circ} \mathrm{C}$ for $90 \mathrm{~min}$

$\downarrow$

NGM plate minus food ( $\pm \mathrm{DMSO}+$ solvent or $\mathrm{drug}), 25^{\circ} \mathrm{C}$ for the observation period

\begin{tabular}{|c|c|c|c|c|c|c|}
\hline & \multicolumn{6}{|c|}{ Moving/total } \\
\hline & $1 \mathrm{~h}$ & $3 \mathrm{~h}$ & $24 \mathrm{~h}$ & $48 \mathrm{~h}$ & $72 \mathrm{~h}$ & $96 \mathrm{~h}$ \\
\hline daf-2(e1391) DMSO, no food & $5 / 38$ & & & & & \\
\hline daf-2(e1391) DMSO, no food + octanol challenge & $30 / 34$ & & & & & \\
\hline N2 DMSO, no food & $25 / 26$ & $19 / 20$ & $8 / 8$ & $6 / 7$ & $3 / 3$ & $0^{\mathrm{a}}$ \\
\hline daf-2(e1391) DMSO, no food & $3 / 22$ & $4 / 20$ & $0 / 20$ & $1 / 22$ & $1 / 22$ & $0 / 21$ \\
\hline unc-64(e246) DMSO, no food & $4 / 24$ & $2 / 25$ & $3 / 25$ & $1 / 25$ & $1 / 22$ & $0 / 22$ \\
\hline
\end{tabular}

Animals (25-40 per plate) were transferred to bacteria-free NGM plates containing DMSO, as shown at the top of the table. For the octanol experiments, we dipped a bristle from a horsehair paintbrush in octanol, held this in front of the nose of the immobile animals, and tallied whether they backed away as expected. For the time course experiments, we periodically assessed spontaneous movement of animals over $96 \mathrm{~h}$. At all time points, the animals still escaped normally in response to tail touch. The steady decline in numbers in the control (N2) group reflected animals that attempted to leave the no-food environment, crawled up the side of the plate, and desiccated off the agar. This represents a typical response of Caenorhabditis elegans strains with a normal drive for food

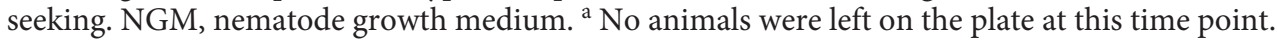

mine, octopamine, tyramine, carbachol, telenzepine, pirenzepine, and atropine were dissolved in water to obtain solubility.

The drugs and DMSO were introduced onto plates $(60-\mathrm{mm}$ NGM-peptone plus food and 90-mm NGM with no peptone) to give the final desired concentrations based on the total agar plus drug-DMSO volumes. The neurotransmitter and drug concentrations evaluated in these experiments were based on either standard values from the literature or levels found effective for other drugs of the same general class [24,25]. The drug and control plates were allowed to dry and equilibrate for $2-3 \mathrm{~h}$ prior to use. The animals were transferred to the drug or control plates and incubated at $25^{\circ} \mathrm{C}$ for $90 \mathrm{~min}$. Then, they were placed on $90-\mathrm{mm}$ NGM plates without food, but with drug-DMSO or dilute acetic acid-DMSO (control) and evaluated for spontaneous movement after 30 and $60 \mathrm{~min}$ on the plates as above. Typically, 25-40 animals were examined in each experiment, with additional repetitions for positive drugs.

\section{Recovery and Blockade of the Recovery Response}

To study recovery after induction of immobility, the animals were first transferred to plates with food and DMSO for $90 \mathrm{~min}$ and then moved to plates with $1 \%$ DMSO without food to induce immobility. After $2 \mathrm{~h}$, the immobile animals were transferred back to the NGM plates with a spot of bacteria in the middle and containing no DMSO (control), DMSO, or drug (and DMSO) at the desired concentration. The animals were placed about one-third of the way from the edge of the plate to the bacterial lawn. At 30 and $60 \mathrm{~min}$, the number of animals on the lawn was counted, and any sluggishness or unresponsiveness to touch was noted. Movement to food was regarded as successful recovery from the diminished motivational state.

\section{Statistical Analysis}

To measure the effect of a treatment on movement, we counted the number of animals that were moving and the total number on the plate, or the number of animals on food in the recovery assay versus the total on the plate. These measures, e.g., moving versus not moving, are nonparametric. Therefore, we used a $\chi^{2}$ test to evaluate whether differences between the treatment groups and the controls were statistically significant. We have previously employed the same statistical approach for the analysis of spontaneous movement in other strains [23]. The $\chi^{2}$ method does not generate standard deviations. To give a sense for variability in the data, we calculated 95\% confidence intervals for 6 representative sets of data. These values averaged $29 \%$ and had a range from 15 to $40 \%$. This means that to be significantly different $(p<0.05)$ from the control group, the percentage of animals moving in the drug treatment groups typically had to be greater than $~ 30-35 \%$ when compared to the average number of animals moving in the control conditions, which was $9.6 \%$ (calculated from 24 experiments). 


\section{Results}

Optimization of Conditions to Produce Immobility

C. elegans has a single receptor, DAF-2, for its $\sim 40$ insulin/IGF-1 proteins. Loss-of-function mutations in the daf-2 gene are associated with constitutive dauer formation (a hibernation-like state of diapause) [26], defects in associative learning [27], and failure to recover pharyngeal pumping during starvation [28]. The latter finding was the starting point for the current studies. We sought to optimize conditions for inducing immobility in C. elegans, including genetic background and environmental influences. Pilot experiments revealed three requirements for inducing long-term immobility: (1) decreased DAF-2 function, (2) $\geq 0.8 \%$ DMSO, and (3) food deprivation. These conditions led to rapid $(<15-20 \mathrm{~min}$ off food) reduction in movement and immobility. DMSO was not harmful at the concentrations used in these experiments - chronic exposure to $1 \%$ DMSO actually extends the life span [29]. The state of immobility was easily reversible by re-exposure to food or removal of DMSO (see below). For the work reported here, we used young adult animals because we wanted to avoid dauer formation and developmental influences.

\section{Genetic Analysis of Immobility Induction}

With the optimized conditions, we compared the behavior of wild-type $\mathrm{N} 2$ controls with animals bearing daf-2 alleles with varying degrees of temperature-induced deficits. Elevated temperature had no effect on the movement of $\mathrm{N} 2$ animals on or off food, in the presence or absence of DMSO (Fig. 1a, b). By contrast, temperature and food deprivation modestly decreased spontaneous movement in daf-2(e1391) animals. However, the combination of elevated temperature, food deprivation, and 1\% DMSO drastically reduced spontaneous movement in this strain (Fig. 1a, b). Elevated temperature did not alter movement via developmental effects of $d a f-2$ loss of function, because the exposure was fairly brief $(\sim 16-18 \mathrm{~h})$ and occurred after larval maturation to adulthood was already complete. This does not appear to be an adult dauer-like phenotype, because muscarinic agonists normally promote dauer recovery [30], whereas the immobile state is maintained by excessive muscarinic signaling (see below).

The animals were not paralyzed by these conditions. They remained fully responsive to touch on the tail with a wire pick and their escape movement was normal (Fig. 1b). In addition, they remained responsive to sensory cues such as octanol, which produces an avoidance response. Immobilized animals with the daf-2(e1391) allele responded normally to octanol by rapid backing (Table 1), which suggested that their sensory function was intact. The animals remained in the immobile state for $96 \mathrm{~h}$ and longer (Table 1), even though during that time they occasionally moved for a few seconds before becoming immobile again. Many remained in the same location on the plate for the duration of the observation period and began to die in place after 12-13 days without food (data not shown). Thus, the animals were fully capable of moving and sensing external cues; however, they failed to show normal motivation to search for food or leave a low-nutrient environment.

By contrast, under identical conditions, we saw no effect on daf-2(m596) animals (Fig. 1c). Gems et al. [31] classified this daf-2 allele as $2 \mathrm{~A}$, which is less severe than the class 2D allele of $e 1391$, based on their different phenotypes including dauer formation, life span, L1 arrest, and brood size. Although not shown, animals with the class $1 \mathrm{~A}$ allele $e 1371$ were not immobilized by these conditions, whereas the more severe allele e979 produced similar outcomes to $e 1391$. Therefore, the severity of the deficits associated with daf-2 alleles with respect to the above phenotypes determined the degree of immobility in our behavioral assay. Unfortunately, the redundancy and number of insulin molecules produced in C. elegans restricted our ability to determine the effects of genetic mutations in the ligand for DAF-2.

Two genes, unc-64 and unc-31, regulate insulin secretion in C. elegans [32], control dauer formation at the restrictive temperature of $27^{\circ} \mathrm{C}$ [33], and, in the case of unc-64, affect recovery of pharyngeal pumping during starvation, which requires insulin signaling [28]. UNC64 (syntaxin) is involved in release from both dense-core vesicles and synaptic vesicles, whereas UNC-31 $\left(\mathrm{Ca}^{++}\right.$ dependent activator protein for secretion, CAPS) mainly regulates release from dense-core vesicles. Therefore, we evaluated animals with loss-of-function mutations in these genes for induction of immobility. Animals with the unc-64(e246) allele showed high levels of immobility very similar to daf-2(e1391) (Fig. 1c). Once again, the animals still responded to touch, indicating that they were not paralyzed, and they remained immobile for 96 $\mathrm{h}$ (Table 1). The unc-31(e169) animals moved at a lower basal rate but were not adversely affected by DMSO and food deprivation. In fact, their spontaneous movement increased with short-term food deprivation and DMSO compared to their behavior on food - the opposite of what was observed in daf-2(e1391) and unc-64(e246) animals. Greater movement of unc-31 strains off food is an established phenotype of mutant animals. Despite near-
100

Mol Neuropsychiatry 2017;3:97-107 DOI: $10.1159 / 000478049$
Dagenhardt/Trinh/Sumner/Scott/ Aamodt/Dwyer 
Fig. 1. Characterization of the immobility response of daf-2(e1391) animals. a We compared the spontaneous movement of wild-type N2 and daf-2(e1391) animals grown at 15 or $25^{\circ} \mathrm{C}$ under different conditions: food, food plus DMSO, no food, and no food plus DMSO, as indicated in the figure. A $\chi^{2}$ analysis revealed significant differences from the appropriate control group (food with no DMSO or food plus DMSO), as noted with the asterisks: ${ }^{* *} p<$ 0.01 . b Still frames from video clips revealing spontaneous movement (upper two rows) or locomotion in response to tail touch (bottom row). The time elapsed in seconds is shown at the lower right-hand corner of each frame. The nose moved slightly from frame 1 to frame 2 of the daf2(e1391) panel in the middle, otherwise the animal remained in the same place for the entire 15-s video, which is characteristic of this strain. The normal sinusoidal movements in response to touch continued well beyond the frames shown in the bottom row. c We evaluated 3 mutant strains to determine if they became immobile in response to brief food deprivation plus DMSO exposure. We found significant differences $\left({ }^{* *} p<0.01\right)$ when comparing $u n c$ 64(e246) animals off food plus DMSO with those on food plus DMSO, unc-31(e169) animals off food with those on food, and unc-31(e169) animals off food plus DMSO with those on food plus DMSO.

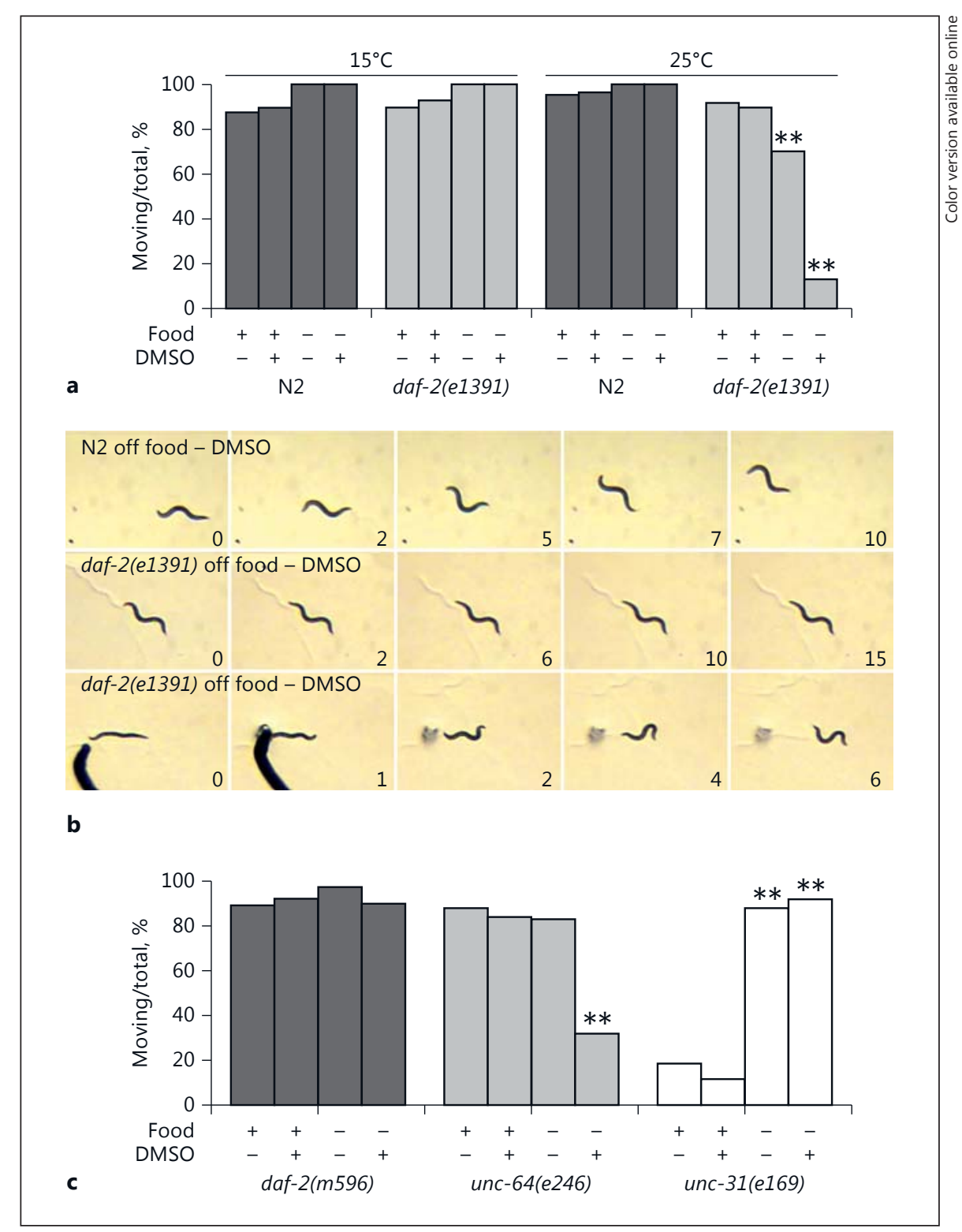

ly identical phenotypes otherwise including sluggish movement at $15^{\circ} \mathrm{C}$, unc-31(e169) animals clearly behaved differently from unc-64(e246) animals in the immobility assay. Cai et al. [34] reported that genetic interactions with ida-1 (IA-2, a protein tyrosine phosphataselike receptor) produced opposite effects in unc-31 (suppression) versus unc-64 animals (enhancement) on dauer formation and aldicarb sensitivity. This confirms the independent functions of these two gene products, despite direct interactions between them, and may be related to the differences observed here. Together with the differential responses of the daf-2 alleles, the data

Insulin Signaling and Diminished Motivation suggest a richness and subtlety in the genetic control of the response.

\section{Pharmacological Reversal of Immobility}

We hypothesized that it should be possible to overcome the induction of immobility with the right pharmacological agent(s). We evaluated various neurotransmitters for their effects on immobility in daf-2(e1391) and unc-64(e246) animals. At concentrations that produced physiological responses such as egg laying and altered foraging, dopamine, octopamine, and tyramine did not affect immobility in these two strains (Fig. 2a). Serotonin 


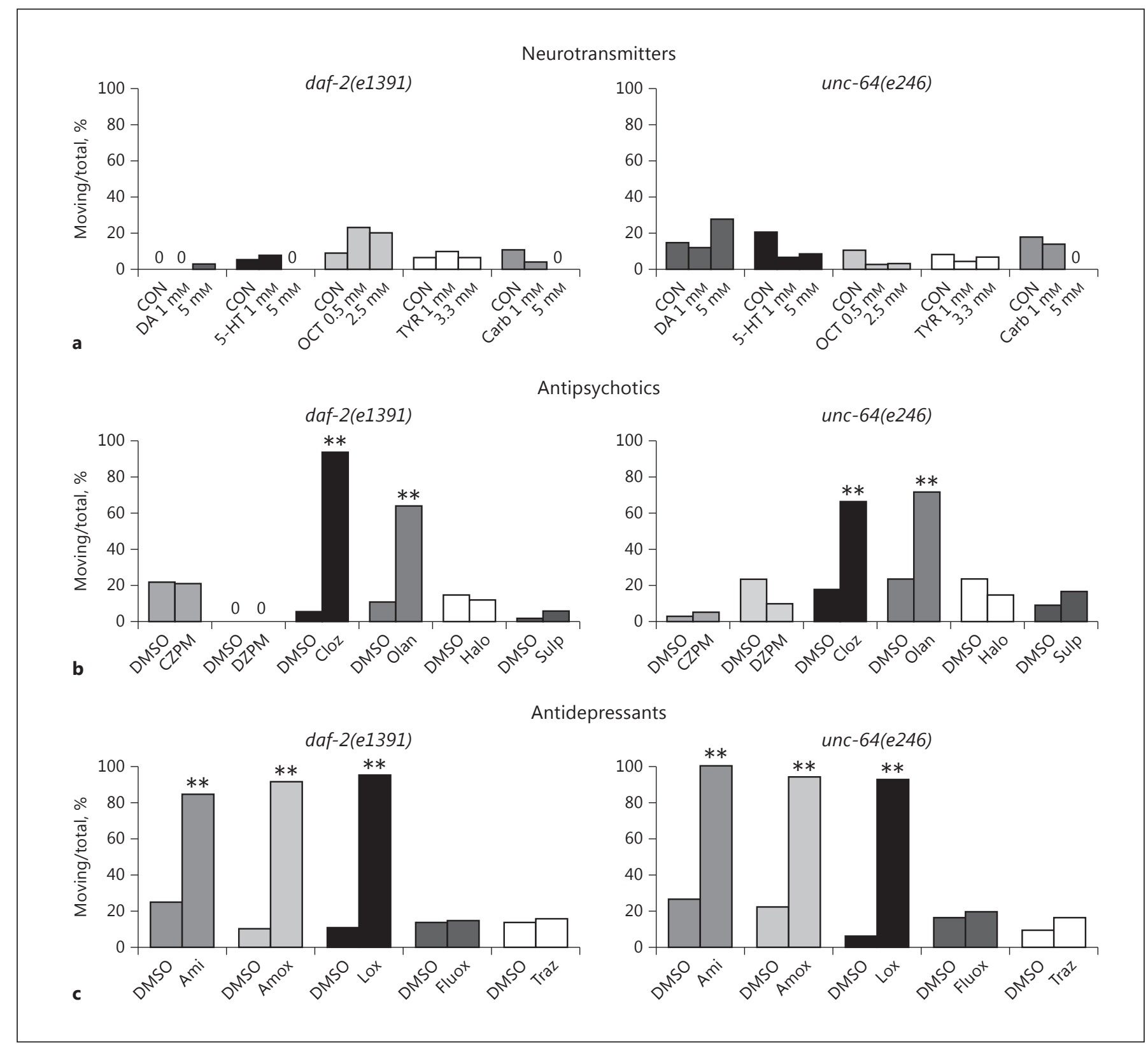

Fig. 2. Reversal of immobility with pharmacological agents. a Dopamine (DA), serotonin (5-HT), octopamine (OCT), tyramine (TYR), and carbachol (Carb) were evaluated for their effects on spontaneous movement in the immobility assay at the concentrations shown in the graph. Zeroes are included in this figure to indicate results where columns are lacking. $\mathbf{b}$ The benzodiazepines clonazepam (CZPM) and diazepam (DZPM) and the antipsychotic drugs clozapine (Cloz), olanzapine (Olan), haloperidol (Halo), and sulpiride (Sulp) were tested for their effectiveness in reducing immobility in the movement assay. They were evaluated at several concentrations, and the results depicted here were obtained with $160 \mu$ M. Significant differences from the control (DMSO) group are indicated with asterisks $(* * p<0.01)$ in this figure. c The antidepressant drugs amitriptyline (Ami), amoxapine (Amox), fluoxetine (Fluox), and trazodone (Traz) and the atypical antipsychotic loxapine (Lox) were tested for their ability to correct spontaneous movement. The data depicted here were obtained with a drug concentration of $160 \mu \mathrm{M}$. Significant differences are indicated by asterisks $\left({ }^{* *} p<0.01\right)$. 
Fig. 3. Pharmacological basis for reversal of immobility. a The serotonergic (5-HT) antagonists ritanserin (Ritan), cyproheptadine (Cypro), and metergoline (Meter) reduced immobility in the spontaneous movement assay. The data shown here were obtained with $160 \mu \mathrm{M}$ drug. b The nonselective muscarinic cholinergic ( $\mathrm{mACh}$ ) antagonist atropine and the $\mathrm{M}_{1}$ receptor-selective antagonists pirenzepine (Pirenz) and telenzepine (Telenz) were evaluated at final drug concentrations of $2 \mathrm{mM}$ (atropine) and $160 \mu \mathrm{M}$ (pirenzepine and telenzepine). Significant stimulation of spontaneous movement in comparison to the DMSO control is indicated with asterisks $\left({ }^{* *} p<0.01\right)$.

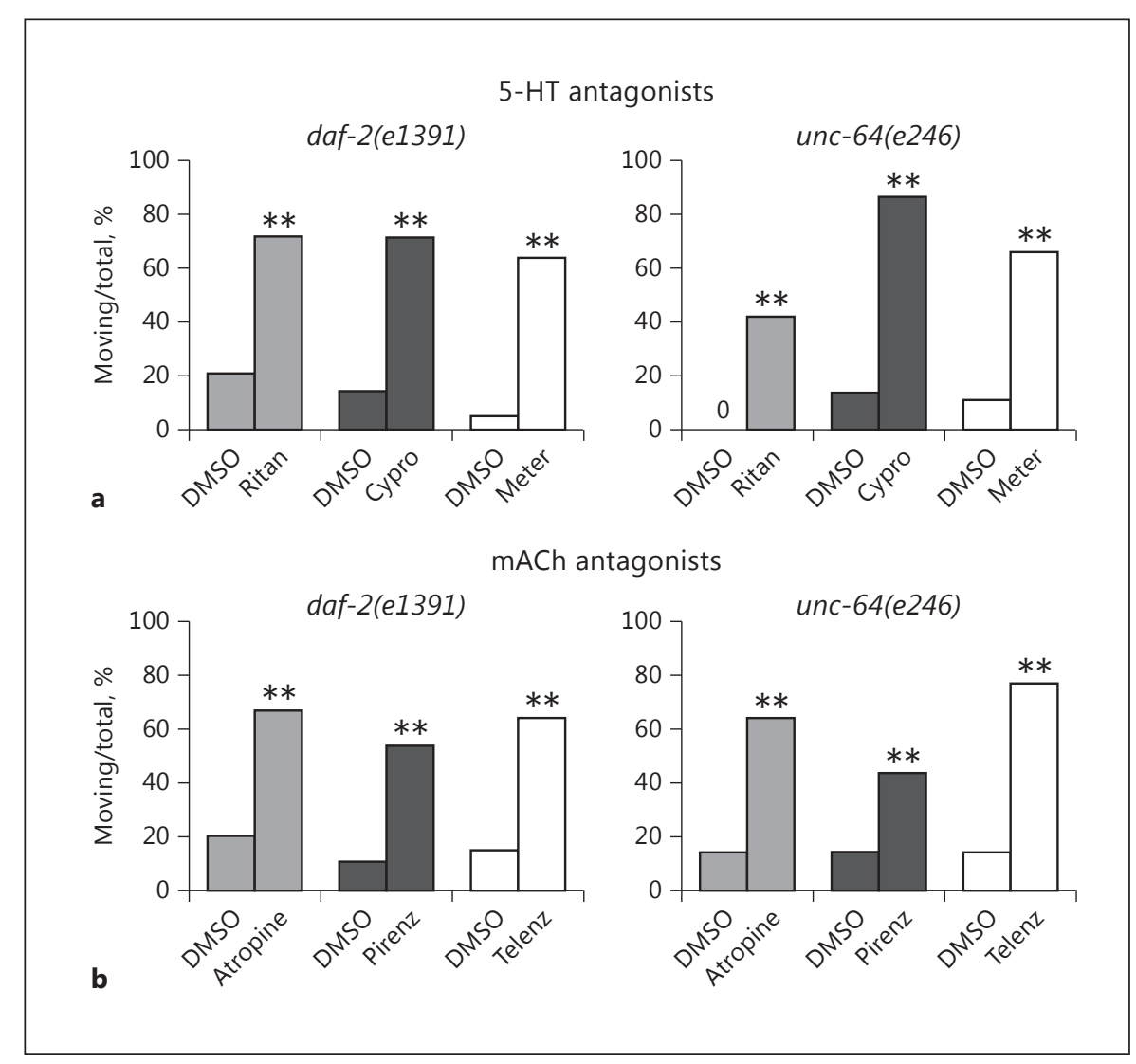

and the cholinergic agonist carbachol also failed to stimulate spontaneous movement in the assay and appeared to further diminish basal activity (see below).

We initially thought our model of immobility might be a protophenotype for catatonia. Therefore, we tested drugs known to treat this condition, i.e., benzodiazepines and the second-generation antipsychotics clozapine and olanzapine. As seen in Figure 2b, clonazepam and diazepam did not correct the immobility of daf-2(e1391) and unc-64(e246) animals. At concentrations above $250 \mu \mathrm{M}$, these drugs began to impair responsiveness of the animals. By contrast, clozapine and olanzapine both partially restored spontaneous movement in the assay (Fig. 2b). However, antipsychotic drugs highly selective for $\mathrm{D}_{2}$ dopamine receptors (haloperidol and sulpiride) failed to reverse immobility (Fig. 2b), suggesting that the effects of clozapine and olanzapine were not mediated by dopamine receptors.

Because reduction of immobility in the forced swimming test is interpreted as an antidepressant effect in rodents, we speculated that established antidepressant drugs might likewise overcome immobility in our system. We evaluated several older tricyclic drugs, fluoxetine (the

Insulin Signaling and Diminished Motivation original serotonin-selective reuptake inhibitor) and trazodone (a mixed 5- $\mathrm{HT}_{2 \mathrm{~A} / 2 \mathrm{C}}$ antagonist and serotoninselective reuptake inhibitor). Amoxapine, amitriptyline, loxapine (methylated amoxapine, an atypical antipsychotic), and imipramine (data not shown) all produced a dramatic increase in spontaneous movement during food deprivation on DMSO (Fig. 2c). The locomotion was essentially normal, with periods of traveling interspersed with sharp turns and reversals. By contrast, fluoxetine and trazodone failed to reduce immobility (Fig. 2c). Many additional drugs had no effect on spontaneous movement, including nicotine, caffeine, flunarizine, buspirone, diltiazem, and nifedipine (data not shown), which attests to the selectivity of the effects. Furthermore, drugs (e.g., clozapine, loxapine, amitriptyline, atropine, metergoline, ritanserin, and telenzepine) that stimulated spontaneous movement in the immobility assay in the mutant strains did not affect movement in N2 animals.

\section{Serotonergic and Cholinergic Antagonists}

\section{Reduce Immobility}

Because the serotonergic antagonists (clozapine and olanzapine) and muscarinic cholinergic inhibitors (tri-

Mol Neuropsychiatry 2017;3:97-107 
Fig. 4. Inhibition of recovery with serotonin (5-HT) and the muscarinic agonist xanomeline (XNM). Animals previously immobilized by DMSO and food deprivation were transferred near the edge of plates with a central lawn of bacteria in the absence or presence of DMSO, as indicated. After $1 \mathrm{~h}$, the number of animals that reached food was counted. The presence of serotonin or xanomeline (at the concentrations listed) significantly reduced recovery, as shown by the asterisks: ${ }^{*} p<0.05,{ }^{* *} p<$ 0.01 .

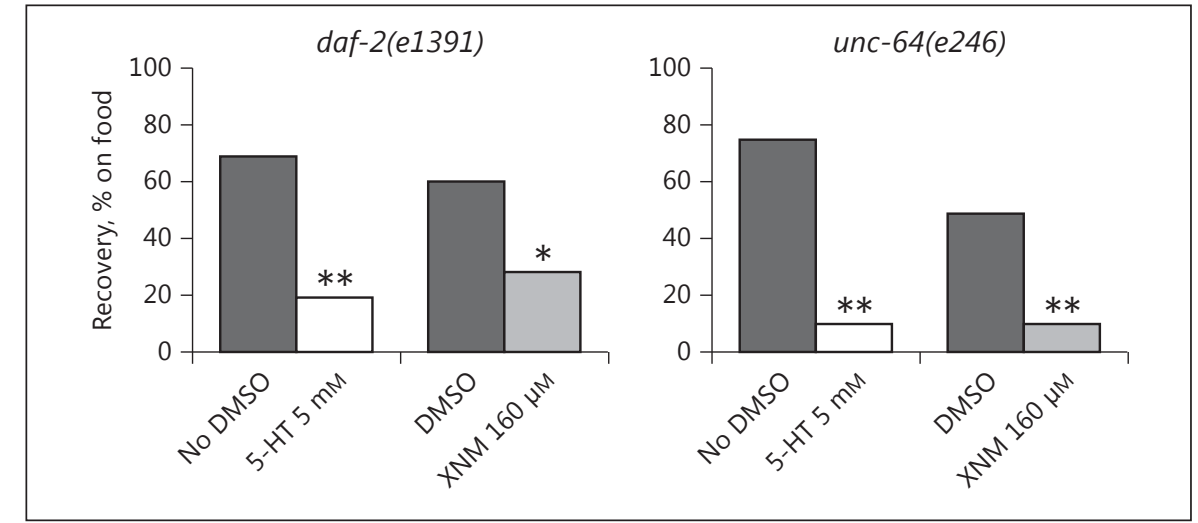

cyclic antidepressants) reduced immobility, we explored the role of serotonin and acetylcholine in the response. Furthermore, serotonin and carbachol appeared qualitatively to cause sluggishness in the mutant animals. Several serotonergic antagonists, including ritanserin (5- $\left.\mathrm{HT}_{2 / 1 \mathrm{C}}\right)$, cyproheptadine $\left(5-\mathrm{HT}_{2 / 1 \mathrm{C}}\right)$, and metergoline $\left(5-\mathrm{HT}_{2 / 1 \mathrm{D} / 7}\right)$, largely prevented the onset of immobility caused by food deprivation/DMSO (Fig. 3a) and improved the foraging behavior of both strains.

To evaluate the role of acetylcholine, we studied the effects of the nonselective muscarinic antagonist atropine and the $M_{1}$ receptor-selective antagonists pirenzepine and telenzepine. The muscarinic agents clearly stimulated greater spontaneous movement in the assay (Fig. 3b), although they were generally less efficacious than the tricyclic antidepressants. These data confirm that acetylcholine, like serotonin, is somehow involved in the suppression of spontaneous movement observed in our system and implicates muscarinic receptors as a major target.

\section{Recovery from Immobility}

In pilot studies, we found that the immobility induced by food deprivation/DMSO exposure was rapidly reversed by reintroducing animals to plates with food in either the absence or presence of DMSO. Therefore, we sought to test whether serotonin and the $M_{1}$ receptorselective drug xanomeline prevented this recovery response. Animals that were immobile after $2 \mathrm{~h}$ on bacteriafree plates with DMSO were transferred to the outer edges of plates with a spot of bacteria in the center, and after $60 \mathrm{~min}$ the number of animals on food in each group was counted. With both mutant strains, recovery was significantly reduced in the presence of serotonin or xanomeline (Fig. 4). Animals that failed to reach the bacterial lawn tended to be immobile, although they were still respon- sive to touch. The results confirm that high levels of serotonergic and cholinergic signaling contribute to the induction/maintenance of immobility.

\section{Discussion}

Here, we describe the characterization of a novel immobility response produced as a consequence of genetic loss of function in insulin receptor signaling and acute food deprivation in the presence of DMSO. The immobility is not due to paralysis, sensory disturbance, or defective neuromuscular function, because the animals still respond normally to touch or aversive chemicals. Rather, the immobile state appears to reflect diminished motivation and failure to initiate goal-directed behavior - foodseeking and foraging. Perhaps, the most extraordinary aspect of this response is the observation that animals will remain in essentially the same place on plates without bacteria for $>96 \mathrm{~h}$, which is contrary to normal survival imperatives aimed at finding food. They will actually perish in place rather than searching for food or trying to escape.

Immobile states in vertebrates can be induced by stress (forced swimming) or acute restraint (tonic immobility and death feigning) and are considered models for MDD $[19,21]$ and catatonia $[35,36]$, respectively. Animals in these states are still responsive to their environment. From the current work, we extend the induction of responsive immobility to the invertebrate C. elegans. A common thread among these various states is a striking reduction in goal-directed behavior or internal drive. This might also reflect an adaptive response aimed at matching the behavioral output with expected rewards (risk-benefit analysis) or conserving efforts when reward 
is unlikely - a strategy that predisposes to avolition and apathy in the context of affective disorders.

Diminished motivation can present as a stand-alone syndrome in man $[10,15]$, but also gives rise to the main negative symptoms of MDD (anhedonia, apathy) and schizophrenia (avolition, social withdrawal). These symptoms are treated, to varying degrees, with antidepressant drugs [37, 38], second-generation antipsychotics including clozapine and olanzapine [39-41], and muscarinic antagonists $[42,43]$. The same drugs have been used to reduce immobility times in the forced swimming test [20,44-46], and, as shown here, they significantly reduce immobility in C. elegans. Taken together, these observations suggest that our immobility model of diminished motivation is a suitable protophenotype [defined in 17] of established endophenotypes relevant to MDD and schizophrenia.

Induction of immobility requires a deficiency in insulin signaling, DMSO, and acute food deprivation. The precise role of DMSO is not known. Several recognized effects of this agent may be relevant: (1) DMSO inhibits binding of insulin to its receptor [47]; (2) it increases quantal synaptic output at the neuromuscular junction [48]; and (3) it directly inhibits acetylcholinesterase [49]. Of course, other explanations are possible. As to the mechanisms related to acute food deprivation, Wakabayashi et al. [50] have previously shown that serotonin is released during food deprivation and regulates foraging, whereas You et al. [51] found that brief starvation activates muscarinic cholinergic signaling in C. elegans. In the context of insulin receptor defects and DMSO, acute food deprivation may stimulate excessive release or signaling via these two neurotransmitters. This would explain why serotonergic and muscarinic cholinergic antagonists restore normal movement in our system. Because loss of function of syntaxin in unc-64(e246) animals mimics the effects of the daf-2(e1391) allele (albeit slightly weaker), we imagine that diminished syntaxin activity mainly reduces insulin release - a known function of this protein [32].

Both daf-2(e1391) and unc-64(e246) mutations prevent insulin-mediated recovery of pharyngeal pumping during prolonged (24- to 48-h) food deprivation. To account for these findings, we [28] previously proposed that the major signaling molecule Akt downstream of the insulin receptor regulates via phosphorylation a variety of ion channels, including voltage-gated $\mathrm{Ca}^{++}$channels and the ketamine target UNC-68 (ryanodine receptor) [52].

The central role of insulin receptor signaling in regulating goal-directed behavior in C. elegans is intriguing, because it may provide clues about why there is a 2 - to

Insulin Signaling and Diminished Motivation 3-fold increase in MDD among patients with diabetes [4, 5]. Insulin resistance is higher among depressed patients even in the absence of diabetes [53, 54], and apathy/ anhedonia are common symptoms in diabetic patients $[55,56]$. Furthermore, diabetic mice display greater immobility in the forced swimming test, and this is corrected by insulin administration [57]. Based on this apparent conservation of function, we speculate that insulin regulates motivation across species.

The findings reported here with serotonergic and muscarinic antagonists and inhibition of recovery with serotonin and xanomeline confirm the involvement of these pathways in the regulation of motivation. Intriguingly, cyproheptadine, ritanserin, metergoline, and scopolamine have all been reported to treat depression [42, $43,58-61]$, whereas atropine has antidepressant effects in the forced swimming test [20]. There is a notable connection between muscarinic activity and insulin, not only in our system but also involving insulin regulation of muscarinic signaling in GABAergic neurons of the prefrontal cortex [62] - a site of scopolamine's antidepressant action [43].

Because well-established drugs that are used in primary (amitriptyline, amoxapine) or adjunctive therapies (clozapine, olanzapine) for MDD or psychotic depression restore normal goal-directed behavior in our system, we wonder if positive effects in the immobility assay might predict antidepressant activity in man. Although fluoxetine and trazodone failed to reduce immobility in our system, results with these drugs are also negative or mixed in the forced swimming test $[63,64]$. Furthermore, this effort may reveal molecular mechanisms that contribute to diminished motivational states and are shared across evolution. Research with C. elegans has provided new clues about pathogenic processes involved in human neurodegenerative disorders, including Alzheimer and Parkinson disease $[65,66]$. Perhaps, this simple organism can also yield significant insights into human psychiatric illnesses characterized by diminished motivation and avolition/anhedonia.

\section{Acknowledgements}

The authors thank the Department of Psychiatry at the LSU Health Sciences Center at Shreveport for financial support and Dr. Nicholas Goeders (LSU Health Sciences Center at Shreveport) for clonazepam and diazepam. Some strains were provided by the CGC, which is funded by NIH Office of Research Infrastructure Programs (P40 OD010440). Finally, the authors thank an anonymous reviewer, who suggested the immobility response may be adaptive and clinically relevant.

Mol Neuropsychiatry 2017;3:97-107

DOI: $10.1159 / 000478049$ 


\section{Statement of Ethics}

These studies were conducted according to general laboratory ethical guidelines. No human or animal use protocols were required for this work.

\section{Disclosure Statement}

None of the authors have any conflicts of interest to declare.

\section{References}

1 Sakel M: The methodical use of hypoglycemia in the treatment of psychoses. Am J Psychiatry 1937;94:111-129.

2 Dwyer DS, Bradley RJ, Kablinger AS, Freeman AM 3rd: Glucose metabolism in relation to schizophrenia and antipsychotic drug treatment. Ann Clin Psychiatry 2001;13:103113.

3 Venkatasubramanian G, Chittiprol S, Neelakantachar N, Naveen MN, Thirthall J, Gangadhar BN, Shetty KT: Insulin and insulin-like growth factor-1 abnormalities in antipsychotic-naïve schizophrenia. Am J Psychiatry 2007;164:1557-1560.

4 Gavard JA, Lustman PJ, Clouse RE: Prevalence of depression in adults with diabetes. An epidemiological evaluation. Diabetes Care 1993;16:1167-1178.

5 Anderson RJ, Freedland KE, Clouse RE, Lustman PJ: The prevalence of comorbid depression in adults with diabetes: a meta-analysis. Diabetes Care 2001;24:1069-1078.

6 Jacobson AM, Samson JA, Weinger K, Ryan CM: Diabetes, the brain, and behavior: is there a biological mechanism underlying the association between diabetes and depression? Int Rev Neurobiol 2002;51:455-479.

7 Bottlender R, Sato T, Groll C, Jäger M, Kunze I, Möller HJ: Negative symptoms in depressed and schizophrenic patients: how do they differ? J Clin Psychiatry 2003;64:954-958.

8 Foussias G, Agid O, Fervaha G, Remington G: Negative symptoms of schizophrenia: clinical features, relevance to real world functioning and specificity versus other CNS disorders. Eur Neuropsychopharmacol 2014;24:693-709.

9 Gold PW, Licinio J, Pavlatou MG: Pathological parainflammation and endoplasmic reticulum stress in depression: potential translational targets through the CNS insulin, klotho, and PPAR- $\gamma$ systems. Mol Psychiatry 2013;18:154-165.

10 Marin RS, Wilkosz PA: Disorders of diminished motivation. J Head Trauma Rehabil 2005;20:377-388.

11 Foussias G, Remington G: Negative symptoms in schizophrenia: avolition and Occam's razor. Schizophr Bull 2010;36:359-369.

12 Velthorst E, Meijer C, Kahn RS, Linszen DH, van Os J, Wiersma D, Breggeman R, Cahn W, de Haan L, Krabbendam L, Myin-Germeys I: The association between social anhedonia, withdrawal and psychotic experiences in general and high-risk populations. Schizophr Res 2012;138:290-294.
13 Hasler G, Drevets WC, Manji HK, Charney DS: Discovering endophenotypes for major depression. Neuropsychopharmacology 2004;29:1765-1781.

14 Padrão G, Mallorquí A, Cucurell D, MarcoPallares J, Rodriguez-Fornells A: Neurophysiological differences in reward processing in anhedonics. Cogn Affect Behav Neurosci 2013;13:102-115.

15 Marin RS: Differential diagnosis and classification of apathy. Am J Psychiatry 1990;147: 22-30.

16 Starkstein SE, Leentjens AFG: The nosological position of apathy in clinical practice. J Neurol Neurosurg Psychiatry 2008;79:10881092.

17 Dwyer DS, Awatramani P, Thakur R, Seeni R, Aamodt EJ: Social feeding in Caenorhabditis elegans is modulated by antipsychotic drugs and calmodulin and may serve as a protophenotype for asociality. Neuropharmacology 2015;92:56-62.

18 Anderson DJ, Adolphs R: A framework for studying emotions across species. Cell 2014; 157:187-200

19 Porsolt RD, Anton G, Blavet N, Jalfre M: Behavioural despair in rats: a new model sensitive to antidepressant treatments. Eur J Pharmacol 1978;47:379-391.

20 Chau DT, Rada P, Kosloff RA, Taylor JL, Hoebel BG: Nucleus accumbens muscarinic receptors in the control of behavioral depression: antidepressant-like effects of local $\mathrm{M}_{1}$ antagonist in the Porsolt swim test. Neuroscience 2002;104:791-798.

21 Petit-Demouliere B, Chenu F, Bourin M: Forced swimming test in mice: a review of antidepressant activity. Psychopharmacology (Berl) 2005; 177:245-255.

22 Brenner S: The genetics of Caenorhabditis elegans. Genetics 1974;77:71-94.

23 Kasap M, Bonnett K, Aamodt EJ, Dwyer DS: Akinesia and freezing caused by $\mathrm{Na}^{+}$leak-current channel (NALCN) deficiency corrected by pharmacological inhibition of $\mathrm{K}^{+}$channels and gap junctions. J Comp Neurol 2017;525: 1109-1121.

24 Weeks KR, Dwyer DS, Aamodt EJ: Antipsychotic drugs activate $C$. elegans Akt pathway via the DAF-2 insulin/IGF-1 receptor. ACS Chem Neurosci 2010;1:463-473.

25 Dwyer DS, Aamodt E, Cohen B, Buttner EA: Drug elucidation: invertebrate genetics sheds new light on the molecular targets of CNS drugs. Front Pharmacol 2014;5:177.
26 Riddle DL: The dauer larva; in Wood WB (ed): The Nematode Caenorhabditis elegans. Long Island, Cold Spring Harbor Laboratory, 1988, pp 393-412.

27 Murakami H, Bessinger K, Hellmann J, Murakami S: Aging-dependent and -independent modulation of associative learning behavior by insulin/insulin-like growth factor-1 signal in Caenorhabditis elegans. J Neurosci 2005;25:10894-10904.

28 Dwyer DS, Aamodt EJ: Insulin/IGF-1 signaling, including class II/III PI3Ks, $\beta$-arrestin and SGK-1, is required in C. elegans to maintain pharyngeal muscle performance during starvation. PLoS One 2013;8:e63851.

29 Wang X, Wang X, Li L, Wang D: Lifespan extension in Caenorhabditis elegans by DMSO is dependent on sir-2.1 and daf-16. Biochem Biophys Res Comm 2010;400:613-618.

30 Tissenbaum HA, Hawdon J, Perregaux M, Hotez P, Guarente L, Ruvkun G: A common muscarinic pathway for diapause recovery in the distantly related nematode species Caenorhabditis elegans and Ancylostoma caninum. Proc Natl Acad Sci USA 2000;97:460465.

31 Gems D, Sutton AJ, Sundermeyer ML, Albert PS, King KV, Edgley ML, Larsen PL, Riddle DL: Two pleiotropic classes of $d a f-2$ mutation affect larval arrest, adult behavior, reproduction and longevity in Caenorhabditis elegans. Genetics 1998:150:129-155.

32 Ailion M, Inoue T, Weaver CI, Holdcraft RW, Thomas JH: Neurosecretory control of aging in Caenorhabditis elegans. Proc Natl Acad Sci USA 1999;96:7394-7397.

33 Ailion M, Thomas JH: Dauer formation induced by high temperatures in Caenorhabditis elegans. Genetics 2000;156:1047-1067.

34 Cai T, Fukushige T, Notkins AL, Krause M: Insulinoma-associated protein IA-2, a vesicle transmembrane protein, genetically interacts with UNC-31/CAPS and affects neurosecretion in Caenorhabditis elegans. J Neurosci 2004;24:3115-3124.

35 Gallup GG Jr, Maser JD: Tonic immobility: evolutionary underpinnings of human catalepsy and catatonia; in Seligman MEP (ed): Psychopathology: Experimental Models. San Francisco, WH Freeman, 1977, pp 334-357.

36 Moskowitz AK: Scared stiff: catatonia as an evolutionary-based fear response. Psychol Rev 2004;111:984-1002.

Dagenhardt/Trinh/Sumner/Scott/ Aamodt/Dwyer 
37 Fruensgaard K, Hansen CE, Korsgaard S, Nymgaard K, Vaag UH: Amoxapine versus amitriptyline in endogenous depression. A double-blind study. Acta Psychiatr Scand 1979;59:502-508.

38 Sovner RD: The clinical characteristics and treatment of atypical depression. J Clin Psychiatry 1981;42:285-289.

39 Miller DD, Perry PJ, Cadoret RJ, Andreasen NC: Clozapine's effect on negative symptoms in treatment-refractory schizophrenics. Compr Psychiatry 1994;35:8-15.

40 Tollefson GD, Sanger TM, Lu Y, Thieme ME: Depressive signs and symptoms in schizophrenia: a prospective blinded trial of olanzapine and haloperidol. Arch Gen Psychiatry 1998;55:250-258.

41 Alvarez E, Ciudad A, Olivares JM, Bousoño M, Gómez JC: A randomized 1-year followup study of olanzapine and risperidone in the treatment of negative symptoms in outpatients with schizophrenia. J Clin Psychopharmacol 2006;26:238-249.

42 Jaffe RJ, Novakovic V, Peselow ED: Scopolamine as an antidepressant: a systematic review. Clin Neuropharmacol 2013;36:24-26.

43 Wohleb ES, Wu M, Gerhard DM, Taylor SR, Picciotto MR, Alreja M, Duman RS: GABA interneurons mediate the rapid antidepressant-like effects of scopolamine. J Clin Invest 2016;126:2482-2494.

44 Lucki I: The forced swimming test as a model for core and component behavioral effects of antidepressant drugs. Behav Pharmacol 1997; 8:523-532.

45 Bourin, M, Colombel MC, Redrobe JP, Nizard J, Hascoët M, Baker GB: Evaluation of efficacies of different classes of antidepressants in the forced swimming test in mice at different ages. Prog Neuropsychopharmacol Biol Psychiatry 1998;22:343-351.

46 Weiner I, Schiller D, Gaisler-Salomon I, Green A, Joel D: A comparison of drug effects in latent inhibition and the forced swim test differentiates between the typical antipsychotic haloperidol, the atypical antipsychot- ics, clozapine and olanzapine, and the antidepressants imipramine and paroxetine. Behav Pharmacol 2003;14:215-222.

47 van Obberghen E, de Meyts P, Roth J: Inhibition of insulin receptor binding by dimethyl sulfoxide. Biochim Biophys Acta 1979;582: 486-495.

48 Van der Kloot W: The kinetics of quantal releases during end-plate currents at the frog neuromuscular junction. J Physiol 1988;402: 605-626.

49 Sams WM Jr, Carroll NV: Cholinesterase inhibitory property of dimethyl sulfoxide. Nature 1966;212:405.

50 Wakabayashi T, Osada T, Shingai R: Serotonin deficiency shortens the duration of forward movement in Caenorhabditis elegans. Biosci Biotechnol Biochem 2005;69:1767-1770.

51 You Y, Kim J, Cobb M, Avery L: Starvation activates MAP kinase through the muscarinic acetylcholine pathway in Caenorhabditis elegans pharynx. Cell Metab 2006;3:237-245.

52 Sakube Y, Ando H, Kagawa H: An abnormal ketamine response in mutants defective in the ryanodine receptor gene $r y r-1$ (unc-68) in Caenorhabditis elegans. J Mol Biol 1997;267: 849-864.

53 Hung Y-J, Hsieh C-H, Chen Y-J, Pei D, Kuo S-W, Shen D-C, Sheu W-H, Chen Y-C: Insulin sensitivity, proinflammatory markers and adiponectin in young males with different subtypes of depressive disorder. Clin Endocrinol 2007;67:784-789.

54 Kan C, Silva N, Hill Golden S, Rajala U, Timonen $\mathrm{M}$, Stahl D, Ismail K: A systematic review and meta-analysis of the association between depression and insulin resistance. Diabetes Care 2013;36:480-489.

55 Bruce DG, Nelson ME, Mace JL, Davis WA, Davis TM, Starkstein SE: Apathy in older patients with type 2 diabetes. Am J Geriatr Psychiatry 2015;23:615-621.

56 Carter J, Swardfager W: Mood and metabolism: anhedonia as a clinical target in type 2 diabetes. Psychoneuroendocrinology 2016; 69:123-132.
57 Gupta D, Kurhe Y, Radhakrishnan M: Antidepressant effects of insulin in streptozotocin induced diabetic mice: modulation of brain serotonin system. Physiol Behav 2014;129: 73-78.

58 Greenway SE, Pack AT, Greenway FL: Treatment of depression with cyproheptadine. Pharmacotherapy 1995;15:357-360.

59 Bersani G, Pozzi F, Marini S, Grispini A, Pasini $\mathrm{A}$, Ciani N: $5-\mathrm{HT}_{2}$ receptor antagonism in dysthymic disorder: a double-blind placebocontrolled study with ritanserin. Acta Psychiatr Scand 1991;83:244-248.

60 Kriston L, von Wolff A, Westphal A, Hölzel LP, Härter M: Efficacy and acceptability of acute treatments for persistent depressive disorder: a network meta-analysis. Depress Anxiety 2014;31:621-630.

61 Turner EH, Schwartz PJ, Lowe CH, Nawab SS, Feldman-Naim S, Drake CL, Myers FS, Barnett RL, Rosenthal NE: Double-blind, placebo-controlled study of single dose metergoline in depressed patients with seasonal affective disorder. J Clin Psychopharmacol 2002; 22:216-220.

$62 \mathrm{Ma} \mathrm{XH,} \mathrm{Zhong} \mathrm{P,} \mathrm{Gu} \mathrm{Z,} \mathrm{Feng} \mathrm{J,} \mathrm{Yan} \mathrm{Z:} \mathrm{Mus-}$ carinic potentiation of $\mathrm{GABA}_{\mathrm{A}}$ receptor currents is gated by insulin signaling in the prefrontal cortex. J Neurosci 2007;23:11591168.

63 Kulkarni SK, Dhir A: Effect of various classes of antidepressants in behavioral paradigms of despair. Prog Neuropsychopharmacol Biol Psychiatry 2007;31:1248-1254.

64 Enginar N, Yamantürk-Çelik P, Nurten A, Güney DB: Learning and memory in the forced swimming test: effects of antidepressants having varying degrees of anticholinergic activity. Naunyn Schmiedebergs Arch Pharmacol 2016;389:739-745.

65 Driscoll M, Gerstbrein B: Dying for a cause: invertebrate genetics takes on human neurodegeneration. Nat Rev Genet 2003;4:181-194.

66 Li J, Le W: Modeling neurodegenerative diseases in Caenorhabditis elegans. Exp Neurol 2013;250:94-103. 